\title{
Disseminated Cryptococcosis Presenting with Adrenal Insufficiency and Meningitis: Resistant to Prolonged Antifungal Therapy but Responding to Bilateral Adrenalectomy
}

\author{
Akira Takeshita, Hideki NakazaWA*, Hiroshi AkiYama*, Kazuo Takeuchi**, Ryuko KawaI***, \\ Kenichi OoHashi*** and Yoshimasa SHISHIbA
}

\begin{abstract}
A case of disseminated cryptococcosis with features of primary adrenal insufficiency and meningitis in an immunocompetent host is presented. Despite antifungal chemotherapy, neither meningitis nor bilateral adrenal gland enlargement was improved. Aspiration biopsy of the adrenal gland revealed necrotic tissue with numerous fungi, suggesting that the adrenal glands were the focus of the persistent fungemia. Removal of bilateral adrenal glands led to improvement by making the patient more sensitive to antifungal chemotherapy.
\end{abstract}

(Internal Medicine 31: 1401-1405, 1992)

Key words: Addison's disease, cryptococcus neoformans, fungemia

\section{Introduction}

Disseminated cryptococcus neoformans infection commonly occurs in immunocompromised patients. In contrast, there are only a few reports that describe disseminated cryptococcosis in normal hosts $(1-3)$. We report a patient with cryptococcal adrenal insufficiency and meningitis who had a normal immunologic status. In this patient, interestingly, the surgical removal of adrenal glands, which were thought to be the focus of fungemia, led to successful treatment.

\section{Case Report}

A 50-year-old Japanese man had been in good health until six months prior to admission to his local hospital, in August 1990, when he developed anorexia, weight loss, nausea, and increased skin pigmentation.

The following serum electrolyte values were obtained: sodium, $119 \mathrm{mEq} / \mathrm{L}$; potassium, $5.8 \mathrm{mEq} / \mathrm{L}$; and chloride, $84 \mathrm{mEq} / \mathrm{L}$. Abdominal ultrasonography and computed tomography (CT) scans demonstrated bilateral enlargement of the adrenal glands. Ultrasonically guided adrenal biopsy was attempted, but failed because he could not hold his breath. Under the tentative diagnosis of adrenal gland enlargement by metastasis and adrenal insufficiency, he was treated with intravenous $100 \mathrm{mg}$ of hydrocortisone every 8 hours for the first day and saline infusion, which improved his symptoms. Hydrocortisone therapy was taperd to an oral maintenance dose. He was then transferred to Toranomon Hospital in September 1990 for further evaluation and management of his suspected adrenal insufficiency.

Physical examination at the time of admission revealed a dehydrated man with generalized pigmentation. He was $166 \mathrm{~cm}$ tall and weighed $76 \mathrm{~kg}$. His blood pressure was $116 / 76 \mathrm{mmHg}$. Admission laboratory data showed a white blood cell count of $12,000 / \mathrm{mm}^{3}$, a hematocrit of $34.6 \%$, and the following serum chemistry levels: sodium, $138 \mathrm{mEq} / \mathrm{L}$; potassium, $3.9 \mathrm{mEq} / \mathrm{L}$; chloride, $102 \mathrm{mEq} / \mathrm{L}$; bicarbonate, $23 \mathrm{mEq} / \mathrm{L}$; creatinine, $1.2 \mathrm{mg} /$ $\mathrm{dL}$; and urea nitrogen, $17 \mathrm{mg} / \mathrm{dL}$. Liver function tests, albumin, total protein, clacium, and inorganic phosphate values were normal. The urinary 17-OHCS excretion was $1.0 \mathrm{mg} /$ day and $17-\mathrm{KS}$ excretion was $1.4 \mathrm{mg} /$ day. The plasma adrenocorticotropic hormone (ACTH) level was elevated to $443 \mathrm{pg} / \mathrm{ml}$ (normal $<60 \mathrm{pg} / \mathrm{ml}$ ). An ACTH loading test ( $250 \mu \mathrm{g}$ of intramuscule cosyntropin) failed to induce a rise in the serum or urinary cortisol levels.

A diagnosis of primary adrenocortical insufficiency was made, and he was maintained on a daily dose of

From the Division of Endocrinology and Metabolism, *the Division of Endocrine Surgery, **the Division of Gastroenterology, and ***the Department of Pathology, Toranomon Hospital, Tokyo

Received for publication June 15, 1992; Accepted for publication October 21, 1992

Reprint requests should be addressed to Dr. Yoshimasa Shishiba, the Division of Endocrinology and Metabolism, Toranomon Hospital, 2-2-2, Toranomon, Minato-ku, Tokyo 105, Japan 
$30 \mathrm{mg}$ of hydrocortisone. A CT scan of the abdomen demonstrated bilateral adrenal enlargement measuring approximately $3 \times 4 \mathrm{~cm}$. The chest radiograph on admission showed no pulmonary infiltrates or nodules, and the cardiac silhouette and vasculature were normal. A PPD skin test gave an area of redness, $9 \times 10 \mathrm{~mm}$ in diameter, in 48 hours without induration. Antibody against adrenocortical cells was negative. Magnetic resonance (MR) imaging of the head with gadolinium (Gd) contrast demonstrated an empty sella (4), but there was normal pituitary function except for a high basal ACTH level. There was thus no evidence to indicate that the etiology of his Addison's disease was tuberculossis. However, no other pathogenesis was indicated, either. Antituberculous chemotherapy was tentatively started on September 27. Isoniazid, ethambutol, and rifampicin (RFP) were administered orally at doses of $400 \mathrm{mg}, 500 \mathrm{mg}$, and $450 \mathrm{mg}$ daily, respectively. He was discharged on October 11. RFP therapy was discontinued because of increased cortisol catabolism following hepatic microsomal-enzyme induction, even with a hydrocortisone administration dose of up to $45 \mathrm{mg}$ daily during RFP treatment.

While receiving steroid replacement therapy, the patient developed severe headache and became drowsy from May 1991. He was again admitted to Toranomon Hospital on May 10.

His temperature was $35.9^{\circ} \mathrm{C}$, heart rate was $68 /$ minute, and blood pressure was $136 / 72 \mathrm{~mm} \mathrm{Hg}$. Generalized skin pigmentation was noted again. Neurologic evaluation revealed a confused, combative patient. There was no nuchal rigidity. The cranial nerves were grossly intact, and the patient was able to move all his extremities. No focal or lateralizing deficits were identified. The remainder of the physical examination was within normal limits. Admission laboratory data showed a white blood cell count of $10,800 / \mathrm{mm}^{3}$, with $73.1 \%$ neutrophils, $0.1 \%$ eosinophils, $0.8 \%$ basophils, $2.8 \%$ monocytes, and $23.2 \%$ lymphocytes, a hematocrit of $47.8 \%$, and the following serum chemistry levels: sodium, $124 \mathrm{mEq} / \mathrm{L}$; potassium, $4.9 \mathrm{mEq} / \mathrm{L}$; chloride, $82 \mathrm{mEq} / \mathrm{L}$; bicarbonate, $23 \mathrm{mEq} / \mathrm{L}$; creatinine, $1.2 \mathrm{mg} / \mathrm{dL}$; and urea nitrogen, $23 \mathrm{mg} / \mathrm{L}$. On the day of admission, his level of consciousness was improved by intramuscular steroids and isotonic saline infusion.

However, the headache, nausea, and vomiting did not improve. Lumbar puncture yielded colorless CSF with a leukocyte counts of $94 / \mathrm{mm}^{3}$ ( $3 \%$ neutrophils, $73 \%$ lymphocytes, and $18 \%$ other cells). CSF protein was elevated to $95 \mathrm{mg} / \mathrm{dl}$, and CSF glucose was markedly reduced to $31 \mathrm{mg} / \mathrm{dl}$ with a concurrent serum glucose of $110 \mathrm{mg} / \mathrm{dl}$. Cryptococcus could be seen in the CSF by light microscopy. The CSF and serum cryptococcal antigen titers were $1: 64$ and $1: 32$, respectively, and culture of the CSF revealed the growth of cryptococcus. Sputum and urine cultures for fungus were negative. Plain and Gd-DTPA-enhanced MR images of the brain and spinal cord were normal except for the previously noted empty sella. There was no meningeal enhancement or evidence of an infarct, hemorrhage, granuloma, hydrocephalus, or periventricular edema $(5,6)$.

Evaluation of the patient's immunologic status revealed that the immunoglobulin level, complement components, lymphocyte subsets, and proliferative response to phytohemagglutinin were normal. The serum IgG level was $1,480 \mathrm{mg} / \mathrm{dL}, \mathrm{IgA}$ was $263 \mathrm{mg} / \mathrm{dL}, \mathrm{IgM}$ was $157 \mathrm{mg} / \mathrm{dL}$, and $\mathrm{IgE}$ was $159 \mathrm{U} / \mathrm{ml}$. Monoclonal $\mathrm{IgG}$ was not seen in the CSF (7). Antibodies to human immunodeficiency virus were not detected by two separate examinations approximately six months apart.

Under the diagnosis of cryptococcal meningitis, fluconazole was administered intravenously at a dose of $200 \mathrm{mg}$ daily. After three weeks of therapy CSF cell count decreased to $61 / \mathrm{mm}^{3}$. However, after four weeks the cell count rose again to $81 / \mathrm{mm}^{3}$. Fluconazole was discontinued, and amphotericin B was administered intravenously at $35 \mathrm{mg}$ daily. However, after five weeks of therapy the CSF cell count had increased to $231 / \mathrm{mm}^{3}$. The patient then received therapy with a combination of fluconazole ( $400 \mathrm{mg}$ daily), amphotericin B, and flucytosine ( $1.5 \mathrm{~g}$ daily). The dose of amphotericin B was reduced due to its adverse effect on renal function. Repeated lumbar puncture was performed. After two months of therapy, the CSF cell count decreased to $35 / \mathrm{mm}^{3}$, and the CSF and serum cryptococcal antigen titers became 1:16 and 1:64, respectively. He was treated for five months, and received a total fluconazole dose of $52.75 \mathrm{~g}$, an amphotericin $\mathrm{B}$ dose of $2,865 \mathrm{mg}$, and a flucytosine dose of $180 \mathrm{~g}$. However, the CSF cell count and the CSF and serum cryptococcal antigen titers did not decrease below $30 / \mathrm{mm}^{3}, 1: 16$, and $1: 64$, respectively. A CT scan of the abdomen demonstrated bilateral adrenal enlargement, which was the same size as previously despite his long-term antituberculous and antifungal therapy (Fig. 1). Small areas of calcification were seen at the margins of the masses. Both T1- and T2-weighted MR images showed adrenal masses that were hypointense relative to liver and kidneys with no Gd-DTPA enhancement (Fig. 2).

Subsequently, ultrasonically guided transhepatic fine needle aspiration biopsy (Majima needle 21G) of the right adrenal was performed to obtain tissue for culture and histologic evaluation. Cryptococcus was identified within the necrotic adrenal tissue (Fig. 3). The tissue fragments were cultured for bacteria, fungi, and acid-fast organisms. All cultures yielded no growth. His antituberculous therapy was then discontinued.

Bilateral adrenalectomy was performed on November 8,1991 . The glands were approximately $8 \times 4 \times 2 \mathrm{~cm}$ and weighed approximately $15 \mathrm{~g}$ each (Fig. 4). Histologic studies of the resected adrenal glands showed massive caseating necrosis containing yeast-like particles that was diagnostic for Cryptococcus neoformans (Fig. 5). 
prevent relapse, as a small number of cryptococcus could still be seen in the sediment of centrifuged CSF by light microscopy.

\section{Discussion}

In Japan, tuberculosis is the most frequent cause of primary adrenal insufficiency. From 1972 to 1981, tuberculosis accounted for $47 \%$ of 168 patients with Addison's disease in Japan. With a gradual decrease in the prevalence of this disease, however, the proportion of autoimmune adrenal insufficiency has increased (32.7\% of the patients) (8). The present patient had no known history of tuberculosis and chemotherapy for tuberculosis failed to improve his adrenal insufficiency.

Disseminated cryptococcus neoformans infection commonly occurs in immunocompromised patients such as those with acquired immunodeficiency syndrome (AIDS) (9-12) or lymphoma, patients who have received steroid or immunosuppressive therapy, and those with hypogammaglobulinemia (13). Both cell-mediated (14) and antibody-mediated (15) immunity play an important role in the defense against cryptococcal infection. However, disseminated cryptococcosis can also develop in apparently normal individuals $(1-3)$.

Disseminated cryptococcosis may involve the lungs, central nervous system, skin, liver, kidneys, lymph nodes, heart, spleen, pancreas, ovaries, skeletal muscle, gastrointestinal tract, adrenals, and other internal organs (16). There exists a divergence of opinion as to the incidence of cryptococcal lesions of the adrenals $(16,17)$, but it is generally agreed that the actual development of Addison's disease is uncommon $(1-3,17)$. The present case of disseminated cryptococcosis causing primary adrenal insufficiency and meningitis occurred in a patient with apprarently normal immunologic function.

Human cryptococcal infection almost always begins as a primary pulmonary focus, following inhalation of the excrement of fowls. The present patient had never kept pigeons but many birds of passage inhabited his large garden during the winter. He liked to walk around his garden which was heavily contaminated with the excrement of fowls. The diagnosis of adrenal involvement was made by ultrasonically guided transhepatic fine needle aspiration of the right adrenal, following the diagnosis of cryptococcal meningitis. This case emphasizes that cryptococcus can be one of the infectious agent which causes of Addison's disease, and that fine needle aspiration biopsy of the adrenal can be used to ascertain the etiology of Addison's disease (3).

There are a few reports on adrenal insufficiency due to cryptococcus in non-immunocompromised hosts. However, the survivors showed a good response to antifungal therapy $(1,3)$. Intravenous amphotericin $\mathrm{B}$ with or without flucytosine, is usually the standard form of therapy (18). Recently, an increasing number of reports have been published concerning AIDS-associated cryptococcal meningitis $(9-12,19-22)$. Fluconazole is an effective alternative to amphotericin B for the primary and maintenance treatment of cryptococcal meningitis (22). In the present case, antifungal therapy (a combination of fluconazole, amphotericin B, and flucytosine) was effective in decreasing the CSF cell count and CSF culture also converted from positive to negative. However, in spite of five months of treatment, the bilateral adrenal masses did not change. The CSF cell count and the cryptococcal antigen titers of CSF and serum did not normalize either. It was reported that serum and CSF titers of $>1: 8$ at one month or more after treatment in patients with cryptococcosis are associated with relapse (18). However, two weeks after bilateral adrenalectomy, the CSF cell count decreased to the normal range and the CSF and serum cryptococcal antigen titers became negative in the present patient. A close association between his adrenal and meningeal involvement was thus apparent.

We conclude that the adrenals provided the focus of fungemia; when the effect of antifungal therapy was insufficient, removal of the focus by surgery was an effective measure for the treatment of the meningitis as well.

\section{References}

1) Nakamura M, Nakashima $T$, Fujishima $M$, et al. Cryptococcosis causing Addison's disease. Fukuoka Igaku Zasshi 71: 639, 1981.

2) Shah B, Taylor HC, Pillay I, Chung-Park M, Dobrinich R. Adrenal insufficiency due to cryptococcosis. JAMA 256: 3247, 1986.

3) Walker BF, Gunthel CJ, Bryan JA, Watts NB, Clark RV. Disseminated cryptococcosis in an apparently normal host presenting as primary adrenal insufficiency: diagnosis by fine needle aspiration. Am J Med 86: 715, 1989.

4) Ambrosi B, Riva E, Ferrario R, Faglia G. Addison's disease and empty sella. J Endocrinol Invest 11: 215, 1988.

5) Chang $\mathrm{KH}$, Han $\mathrm{MH}$, Roh JK, Kim IO, Han MC, Kim CW. Gd-DTPA-enhanced MR imaging of the brain in patients with meningitis: comparison with CT. Am J Roentgenol 154: 809, 1990.

6) Kawahata N, Tanaka Y, Kitajima N, Takatsuka K, Komatsu T. Intracranial granuloma in cryptococcal meningoencephalitis by magnetic resonance imaging (MRI). Shinkeinaika 23: 608, 1985 (in Japanese).

7) Okabe T, Ono S, Hamaguchi K, Nishikawa Y. A case of cryptococcal meningitis with monoclonal IgG in cerebrospinal fluid. Shinkeinaika 27: 293, 1987 (in Japanese)

8) Katou K, Ibayashi H. Annual report of the ministry of health and welfare "Disorders of steroid hormones" research committec, Japan, 1983, p. 6 (in Japanese).

9) Kovacs JA, Kovacs AA, Polis M, et al. Cryptococcosis in the acquired immunodeficicncy syndrome. Ann Intern Med 103: $533,1985$.

10) Zuger A, Louie E, Holzman RS, et al. Cryptococcal disease in patients with acquired immunodeficiency syndrome. Ann Intern Med 104: 234, 1986

11) Chuck SL, Sande MA. Infections with cryptococcus neoformans in the acquired immunodeficiency syndrome. N Engl J Med 321: 


\section{Cryptococcus Adrenalitis and Meningitis}

794, 1989.

12) Clark RA, Greer D, Atkinson W, Valainis GT, Hyslop N. Spectrum of cryptococcus neoformans infection in 68 patients infected with human immunodeficiency virus. Rev Infect Dis 12: $768,1990$.

13) Gupta S, Ellis M, Cesario T, Ruhling M, Vayuvegula B. Disseminated cryptococcal infection in a patient with hypogammaglobulinemia and normal T cell functions. Am J Med 82: 129, 1987.

14) Murphy JW, Moorhead JW. Regulation of cell-mediated immunity in cryptococcosis. J Immunol 128: 276, 1982.

15) Miller GPG, Kohl S. Antibody-dependent leukocyte killing of cryptococcus neoformans. J Immunol 131: 1455, 1983.

16) Lewis JL, Rabinovich S. The wide spectrum of cryptococcal infections. Am J Med 53: 315, 1972.

17) Salyer WR, Moravec CL, Salyer DC, Guerin PF. Adrenal involvement in cryptococcosis. Am J Clin Pathol 60: 559, 1973.
18) Dismukes WE, Cloud G, Gallis HA, et al. Treatment of cryptococcal meningitis with combination amphotericin $B$ and flucytosine for four as compared with six weeks. N Engl J Med 317: 334, 1987.

19) Sugar AM, Stern JJ, Dupont B. Overview: treatment of cryptococcal meningitis. Rev Infect Dis 12: Suppl 3: S338, 1990.

20) Larsen RA, Leal MAE, Chan LS. Fluconazole compared with Amphotericin B plus flucytosine for cryptococcal meningitis in AIDS. Ann Intern Med 113: 183, 1990.

21) Bozzette SA, Larsen RA, Chiu J, et al: A placebo-controlled trial of maintenance therapy with fluconazole after treatment of cryptococcal meningitis in the acquired immunodeficiency syndrome. N Engl J Med 324: 580, 1991.

22) Saag MS, Powderly WG, Cloud GA, et al. Comparison of amphotericin $B$ with fluconazole in the treatment of acute AIDSassociated cryptococcal meningitis. N Engl J Med 326: 83, 1992. 